\title{
Effect of oxidation on the gel properties of porcine myofibrillar proteins and their binding abilities with selected flavour compounds
}

Article

Accepted Version

Creative Commons: Attribution-Noncommercial-No Derivative Works 4.0

Shen, H., Elmore, J. S., Zhao, M. and Sun, W. (2020) Effect of oxidation on the gel properties of porcine myofibrillar proteins and their binding abilities with selected flavour compounds. Food Chemistry, 329. 127032. ISSN 0308-8146 doi: https://doi.org/10.1016/j.foodchem.2020.127032 Available at https://centaur.reading.ac.uk/90752/

It is advisable to refer to the publisher's version if you intend to cite from the work. See Guidance on citing.

To link to this article DOI: http://dx.doi.org/10.1016/j.foodchem.2020.127032

Publisher: Elsevier

All outputs in CentAUR are protected by Intellectual Property Rights law, including copyright law. Copyright and IPR is retained by the creators or other copyright holders. Terms and conditions for use of this material are defined in the End User Agreement. 


\section{CentAUR}

Central Archive at the University of Reading

Reading's research outputs online 
1 Effect of oxidation on the gel properties of porcine myofibrillar proteins and their

13 Corresponding author

14 Weizheng Sun, Professor

15 Tel/Fax: +86 2022236089

16 E-mail: fewzhsun@ scut.edu.cn 
Abstract:

18 In this work, the effect of oxidation induced by hydroxyl radicals on the binding 19 abilities of myofibrillar protein (MP) gels to aldehydes and ketones and their 20 relationship with MP gel properties were investigated. Mild oxidation $\left(0-0.2 \mathrm{mM} \mathrm{H}_{2} \mathrm{O}_{2}\right)$

21 could induce partial unfolding of MP, thus slightly increasing the salt solubility of MP

22 and enhancing the hardness of MP gels. MP suffering a higher oxidative attack could 23 undergo a reduction in water-holding capacity, with increased mobility of water in MP 24 gels. Oxidation could make MP gel more disordered. The ability of oxidised MP gels 25 to bind to flavours decreased as the carbon chain length of the flavour compound 26 increased. MP oxidation only significantly affected the binding of MP gels to hexanal, 27 heptanal, and 2-octanone, while other flavour compounds were not affected.

28 Keywords: myofibrillar proteins; oxidation; gel properties; flavours release; water 29 mobility 


\section{Introduction}

The formation of protein gels in processed muscle foods is an important functionality that can affect the texture and sensory characteristics of the final meat products. Myofibrillar proteins (MP), as the major proteins in muscle, are excellent gelling agents that are largely responsible for the textural and structural characteristics of meat products (Xiong, Blanchard, Ooizumi, \& Ma, 2010).

During meat storage or industrial processing, reactive oxygen species, which include superoxide anions, hydroxyl radicals, peroxyl radicals and lipid oxidation products, play a critical role in the accumulation of oxidative damage in proteins (Zhou, Zhao, Zhao, Sun, \& Cui, 2014a). Types of oxidative damage to muscle proteins can include conformational changes, peptide chain scission and formation of amino acid derivatives or aggregates, leading to changes in physicochemical properties of proteins, which in turn alter the functional properties of proteins, such as gelation, emulsification and the capacity to bind flavours (Sun, Zhou, Sun, \& Zhao, 2013; Xiong et al., 2010). The gel properties of MP, such as rheological properties, water-holding capacity (WHC), texture and microstructure change under oxidative stress (Xiong, Park, \& Ooizumi, 2009).

Food acceptability by consumers is governed to a considerable extent by their organoleptic properties, and mostly by flavour perception (Gierczynski, Guichard, \& Laboure, 2011). Volatile flavour release is largely determined by the tendency of volatile compounds to bind to other ingredients (particularly oils and protein) and by food microstructure (Guichard, 2002). As mentioned above, protein oxidation can affect meat products microstructure, especially gel quality. Some reports have evaluated the abilities of oxidised MP at different oxidation levels to bind to flavour compounds (Cao, Zhou, Wang, Sun, \& Pan, 2018; Zhou et al., 2014a). Thus far, 
55 investigations regarding the binding of oxidised MP gels to flavour compounds are

56 limited. Modifying food microstructure can also control volatile release in foods (Mao,

57 Roos, \& Miao, 2014). Among flavours, the impacts of aldehydes and ketones are of

58 particular interest because of their practical contribution in meat and meat products

59 (Guichard, 2002). Therefore, it is necessary to investigate the behaviour of oxidised MP

60 gels in binding to typical odour-active aldehydes and ketones, to establish the

61 mechanism of flavour release in gelatinous meat products.

62 In this work, MP were exposed to a hydroxyl radical-generating system that is 63 commonly involved in meat and meat products. Examination of the accompanying 64 protein structural changes (sulfhydryl [SH] groups, surface hydrophobicity, salt 65 solubility, particle size distribution) with the results of sodium dodecyl sulfate66 polyacrylamide gel electrophoresis [SDS-PAGE]) and with gel properties (hardness, 67 WHC, microstructure, low-field nuclear magnetic resonance [LF-NMR] relaxation 68 time) was designed to investigate the influence of oxidative modification on MP and 69 MP gels. The phenomena of oxidised MP gels binding to typical aldehyde and ketone 70 compounds were evaluated using headspace analysis followed by gas chromatography71 mass spectrometry. Moreover, selected aldehyde and ketone compounds of various 72 chain lengths were used to evaluate the contributions of molecular structure to the 73 binding phenomena. The relationship between MP gel properties and their binding 74 abilities is discussed.

\section{2. Materials and methods}

77 Fresh porcine muscle (longissimus dorsi) was purchased from a local commercial 78 abattoir (Guangzhou, China), where the pigs were slaughtered at approximately 6 79 months of age following standard industrial procedures. Fat and connective tissue were 
removed before the separation of proteins. Pentanal, hexanal, heptanal, octanal, 2pentanone, 2-heptanone, 5,5'-dithiobis-(2-nitrobenzoic acid) (DTNB) and piperazine$N, N$-bis(2-ethanesulfonic acid) (PIPES) were purchased from Sigma-Aldrich Chemical Co. (St. Louis, MO); 2-hexanone, 2-octanone, propyl gallate and Trolox $\mathrm{C}$ were obtained from Aladdin (Shanghai, China). Bromophenol blue (BPB), thiourea, dithiothreitol and EDTA were obtained from Sinopharm Chemical Reagent Co., Ltd. (Shanghai, China). All other chemicals were of analytical reagent grade at minimum.

\subsection{Preparation of $M P$}

MP were extracted according to the method of Shen, Zhao and Sun (2019), with a slight modification. The $\mathrm{pH}$ of the MP suspension $(0.1 \mathrm{M} \mathrm{NaCl})$ in the last wash was adjusted to 6.25 before centrifugation $\left(2000 \mathrm{~g}, 15 \mathrm{~min}, 4^{\circ} \mathrm{C}\right)$. The concentrations of MP were measured by the Biuret method using bovine serum albumin as a standard. The MP pellet was kept on ice and used within 2 days.

\subsection{Protein oxidation}

MP were suspended $(30 \mathrm{mg} / \mathrm{mL})$ in a $15-\mathrm{mM}$ PIPES buffer containing $0.6 \mathrm{M} \mathrm{NaCl}$ (pH 6.25). To oxidise them, MP suspensions were incubated at $4{ }^{\circ} \mathrm{C}$ for $24 \mathrm{~h}$, using a hydroxyl radical-generating system. The hydroxyl radicals were produced by a $10-\mu \mathrm{M}$ $\mathrm{FeCl}_{3} / 100-\mu \mathrm{M}$ ascorbic acid solution with $1 \mathrm{mM} \mathrm{H} \mathrm{H}_{2} \mathrm{O}_{2}$. Oxidation was terminated by adding propyl gallate/Trolox C/EDTA (1 mM each) (Xiong et al., 2009). The fresh MP suspension $(30 \mathrm{mg} / \mathrm{mL})$ without any hydroxyl radical-generating system or terminating agent was used as the control. The concentrations of MP in the following measurements were adjusted using a $15 \mathrm{mM}$ PIPES buffer ( $\mathrm{pH} 6.25$ ) containing $0.6 \mathrm{M} \mathrm{NaCl}$.

\subsection{Total and reactive $\mathrm{SH}$ groups}

Total SH contents were determined with a DTNB method with some modifications (Zhou, Zhao, Su, \& Sun, 2014b). For determining the level of total SH groups, $1 \mathrm{~mL}$ 
105 MP suspension (4 mg/mL) was mixed with $5 \mathrm{~mL}$ of $0.086 \mathrm{M}$ Tris-Gly buffer $(5 \mathrm{mM}$

106 EDTA, $8 \mathrm{M}$ urea, $0.6 \mathrm{M} \mathrm{NaCl}, \mathrm{pH} 8.0)$ and $30 \mu \mathrm{L}$ of $4 \mathrm{mg} / \mathrm{mL}$ DTNB (0.086 M Tris-

107 Gly buffer, $5 \mathrm{mM}$ EDTA, $0.6 \mathrm{NaCl}, \mathrm{pH}$ 8.0). After incubation at room temperature (25

$108 \pm 1^{\circ} \mathrm{C}$ ) for $30 \mathrm{~min}$, the absorbance at $412 \mathrm{~nm}$ was recorded for the calculation of total

109 SH groups using a molar extinction coefficient of $13,600 \mathrm{M}^{-1} \mathrm{~cm}^{-1}$. Reactive SH groups

110 were prepared by incubating the reaction mixture in the absence of urea. The blank was

111 run with 15-mM PIPES buffer ( $\mathrm{pH} 6.25$ ) containing $0.6-\mathrm{M} \mathrm{NaCl}$.

112 2.5. Surface hydrophobicity

113 The surface hydrophobicity of the MP was measured by the hydrophobic 114 chromophore BPB method (Chelh, Gatellier, \& Santé-Lhoutellier, 2006) with a slight 115 modification. This method can determine the surface hydrophobicity of MP, avoiding 116 the solubilisation step of the myofibrils before the protein hydrophobicity determination.

117 The MP suspension $(1 \mathrm{~mL}, 4 \mathrm{mg} / \mathrm{mL})$ was thoroughly mixed with $100 \mu \mathrm{L}$ BPB (1 $118 \mathrm{mg} / \mathrm{mL})$ and kept at ambient temperature $\left(25 \pm 1^{\circ} \mathrm{C}\right)$ for $10 \mathrm{~min}$ before centrifugation $119\left(5000 \mathrm{~g}, 15 \mathrm{~min}, 25^{\circ} \mathrm{C}\right)$. The absorbance of each supernatant (diluted for 10 times) was 120 determined at $595 \mathrm{~nm}$ against a PIPES buffer blank. A sample with the same treatments 121 in the absence of MP was used as the control. The index of surface hydrophobicity was 122 expressed as the amount of bound BPB, and it was calculated using the following 123 formula (1):

$$
\text { BPB bound }(\mu \mathrm{g})=100 \times\left(\mathrm{A}_{\text {control }}-\mathrm{A}_{\text {sample }}\right) / \mathrm{A}_{\text {control }}
$$

\section{2.6. Salt solubility and MP turbidity}

126 Salt solubility of MP (10 mg/mL) and turbidity of MP suspensions $(1 \mathrm{mg} / \mathrm{mL})$ were 127 determined according to Shen et al. (2019). The salt solubility of MPs was measured 128 after centrifuging $\left(5000 \mathrm{~g}, 25^{\circ} \mathrm{C}\right)$ for $20 \mathrm{~min}$ to separate the salt-soluble fractions from 
129 the insoluble fractions. The result was expressed as the percentage of initial protein 130 concentration.

\section{$131 \quad$ 2.7. Particle size distributions}

132 Particle size distributions of control and oxidised MP were measured with an 133 integrated-laser light scattering instrument (Mastersizer 2000; Malvern Instruments Co.

134 Ltd., Worcestershire, UK). The relative refractive index and absorption were set as 1351.414 and 0.001 , respectively. $\mathrm{D}_{4,3}$ is the mean diameter in volume, and $\mathrm{D}_{3,2}$ is the mean 136 diameter in surface, called the 'Sauter diameter'. $D_{v, 0.5}$ is the size for which $50 \%$ of the 137 sample particles have a lower size and 50\% have an upper size. The specific surface 138 areas (square metres per gram) were also recorded.

139 2.8. Sodium dodecyl sulfate-polyacrylamide gel electrophoresis

140 Sodium dodecyl sulfate-polyacrylamide gel electrophoresis (SDS-PAGE) was 141 performed on MP according to the method described by Zhou et al. (2014b) with a 142 slight modification. Briefly, the MP suspension (4 mg/mL) was mixed in a 1:1 ratio 143 with $50 \mathrm{mM}$ Tris buffer (8 M urea, $2 \mathrm{M}$ thiourea, 3\% (w/v) SDS, 0.05\% BPB and 20\% 144 (v/v) glycerine, $\mathrm{pH} 6.8$ ) with or without $75 \mathrm{mM}$ dithiothreitol. The samples were boiled 145 for 4 min before centrifugation $\left(10,000 \mathrm{~g}, 10 \mathrm{~min}, 25^{\circ} \mathrm{C}\right)$. Next, $9 \mu \mathrm{L}$ of each MP 146 mixture were injected into each gel, comprising a $12 \%$ running gel and a $4 \%$ stacking 147 gel. The electrophoresis was operated at a constant current of $25 \mathrm{~mA}$ using a Mini148 PROTEAN 3 Cell apparatus (Bio-Rad Laboratories, Hercules, CA).

\section{2.9. Gel properties}

150 2.9.1. Preparation of heat-induced gels

151 For gelation, the control and oxidised MP $(30 \mathrm{mg} / \mathrm{mL})$ were prepared for gel property 152 analyses according to the method of Zhou et al. (2014b). The MP suspensions were 153 heated in a water bath from $25^{\circ} \mathrm{C}$ to $72{ }^{\circ} \mathrm{C}$ at $1{ }^{\circ} \mathrm{C} / \mathrm{min}$ increments (kept for $5 \mathrm{~min}$ at 
$15453{ }^{\circ} \mathrm{C}$ and $10 \mathrm{~min}$ at $72{ }^{\circ} \mathrm{C}$ ). After heating, the gels were immediately cooled to room 155 temperature.

\subsubsection{Gel hardness and WHC}

157 Prior to the hardness measurements, gel samples were allowed to equilibrate at room

158 temperature $\left(25 \pm 1^{\circ} \mathrm{C}\right)$ for $1 \mathrm{~h}$. The hardness of MP gels was measured using a cylinder 159 measuring probe (P/0.5S, $12.7 \mathrm{~mm})$ attached to TA-XT Plus Texture Analyzer (Stable 160 Micro Systems Ltd., Godalming, UK) at a constant probe speed of $1.0 \mathrm{~mm} / \mathrm{s}$ at room 161 temperature. The gel hardness was defined as the initial force required to rupture the 162 gels.

163 WHC values for the gels were determined by a centrifugal method (Xia, Kong, Xiong,

$164 \&$ Ren, 2010). Briefly, gel samples (3 g) were centrifuged at $4000 \mathrm{~g}$ for $15 \mathrm{~min}$ at room 165 temperature. The WHC (\%) was expressed using the final weight as a percentage of the 166 weight before centrifugation $\left(6000 \mathrm{~g}, 15 \mathrm{~min}, 4^{\circ} \mathrm{C}\right)$.

167

168

169

170

171

172

173

\subsubsection{Microstructure}

The surface morphologies of control and oxidised MP gels were examined using field emission scanning electron microscopy (FE-SEM, model S-3400N; Hitachi, Japan) at an accelerator voltage of $15 \mathrm{kV}$. Cubic samples (approximately $3 \times 3 \times 3 \mathrm{~mm}$ ) were prepared and snap-frozen in liquid $\mathrm{N}_{2}$ (Zhou et al., 2014a). Before imaging, freezedried gel samples were mounted on a holder with double-sided adhesive tape and sputter-coated with gold (JFC-1200 fine coater; JEOL, Tokyo, Japan). Sample observation and photomicrography were performed at 500× and 2000× magnifications, respectively.

\subsubsection{Low-field NMR relaxation time $\left(T_{2}\right)$}

Low-field NMR relaxation measurements were performed according to a previous method (Zhang, Yang, Tang, Chen, \& You, 2015) with some modifications. 
Approximately $1.6 \mathrm{~g}$ of each gel sample formed in a $2 \mathrm{~mL}$ screw-cap chromatogram vial were placed inside a cylindrical glass tube $(15 \mathrm{~mm}$ in diameter $)$ and inserted into the NMR probe of a Niumag Benchtop Pulsed NMR analyser (Niumag PQ001; Niumag Electric Corporation, Shanghai, China). The analyser was operated at $32{ }^{\circ} \mathrm{C}$ and a resonance frequency of $18 \mathrm{MHz}$. The $\mathrm{T}_{2}$ was measured using the Carr-PurcellMeiboom-Gill sequence with 4 scans, 8000 echoes, $2.0 \mathrm{~s}$ between scans, and $400 \mu \mathrm{s}$ between pulses of $90^{\circ}$ and $180^{\circ}$. The $\mathrm{T}_{2}$ relaxation curves were fitted to a multiexponential curve with the MultiExp Inv Analysis software (Niumag Electric Corporation, Shanghai, China), which used the inverse Laplace transform algorithm.

\subsection{SPME-GC/MS}

A stock solution containing all selected flavours (aldehydes and ketones) was freshly prepared in methanol (HPLC grade) and sealed in brown gas-tight glass bottles to prevent volatilising. The stock solution was then pipetted to control and oxidised MP suspensions $(30 \mathrm{mg} / \mathrm{mL})$, to a final concentration of $1 \mathrm{mg} / \mathrm{kg}$ for each flavour. Each mixture ( $8 \mathrm{~mL}$ protein/control solution $+50 \mu \mathrm{L}$ stock solution) was placed in a $20-\mathrm{mL}$ headspace vial and sealed with a polytetrafluoroethylene (PTFE)-faced silicone septum (Supelco, Bellefonte, PA, USA). For gelation, the control and oxidised MP gels were developed according to Section 2.9.1. The gel vials were stored at $25{ }^{\circ} \mathrm{C}$ for $16 \mathrm{~h}$ to allow equilibration.

The quantities of flavour compounds present in the headspace of gel vials were determined using solid-phase microextraction (SPME) followed by gas chromatography/mass spectroscopy (GC/MS) analysis according to the procedure described by Zhou et al. (2014a). The SPME parameters were as follows: $75 \mu \mathrm{m}$ Carboxen/polydimethylsiloxane (CAR/PDMS) fibre (Supelco, Bellefonte, PA), equilibrated at $45^{\circ} \mathrm{C}$ for $20 \mathrm{~min}$, extracted at $45^{\circ} \mathrm{C}$ for $30 \mathrm{~min}$, desorbed at $220^{\circ} \mathrm{C}$ for 5 
min. GC-MS conditions: TR-Wax column $(30 \mathrm{~m} \times 0.32 \mathrm{~mm} \times 0.25 \mu \mathrm{m}$; J\&W Scientific,

205 Folsom, CA, USA) was used for separation. The carrier gas was high purity helium at 206 a linear flow rate of $20.4 \mathrm{~cm} \mathrm{~s}^{-1}$. The initial GC oven temperature was $38^{\circ} \mathrm{C}$, held for 6 207 min, rising to $105^{\circ} \mathrm{C}$ at a rate of $6^{\circ} \mathrm{C} \mathrm{min}^{-1}$, then raised to $220^{\circ} \mathrm{C}$ at a rate of $15^{\circ} \mathrm{C} \mathrm{min}-$ $208{ }^{1}$, and held at $220^{\circ} \mathrm{C}$ for $5 \mathrm{~min}$. The mass spectrometry conditions were electron 209 ionisation (EI) at $70 \mathrm{eV}$, electron multiplier voltage $350 \mathrm{~V}$, scanning speed $3.00 \mathrm{scans} / \mathrm{s}$, 210 mass range $m / z 33-350$. The results were expressed as the difference in peak areas of 211 flavour compounds between the oxidised MP gels and the control gel, calculated by the 212 following equation (2):

213 Free flavour compound $(\%)=($ peak area protein/peak area control $) \times 100$

\section{2.11. Statistical analysis}

215 Data were expressed as means \pm standard deviations of triplicate determinations.

216 Statistical calculation was investigated by analysis of variance using SPSS 17.0 (SPSS, 217 Inc., Chicago, IL). The means were compared using Duncan's multiple range test ( $p<$ $2180.05)$.

\section{Results and discussion}

3.1. Total and reactive SH groups, surface hydrophobicity, salt solubility and turbidity

The loss of SH groups is one of the primary common characteristics of protein 223 changes under oxidative attack (Xiong et al., 2009). As presented in Table 1, compared 224 with the control, the total and reactive SH contents both decreased continuously upon oxidation with the increase of $\mathrm{H}_{2} \mathrm{O}_{2}$ concentrations $(p<0.05)$. MP are rich in $\mathrm{SH}$ groups that can be readily converted to disulphide linkages (S-S) upon oxidative stress (Cao,

227 True, Chen, \& Xiong, 2016). The decrease in total and reactive SH contents signified 228 that the $\mathrm{SH}$ groups of cysteine were oxidised with the formation of S-S (Sante- 
229 Lhoutellier, Aubry, \& Gatellier, 2007). Cao et al. (2018) also suggested that SH groups

230 in G-actin were susceptible to hydroxyl radicals and easily changed into intermolecular

$231 \mathrm{~S}-\mathrm{S}$. Hence, the generated hydroxyl radicals $\left(0.05-5.0 \mathrm{mM} \mathrm{H}_{2} \mathrm{O}_{2}\right)$ were responsible for

232 the decrease in total and reactive SH contents. In addition, contents of total and reactive

$233 \mathrm{SH}$ also significantly decreased $(p<0.05)$ in $0 \mathrm{mM} \mathrm{H}_{2} \mathrm{O}_{2}$ compared with the control,

234 which may be associated with oxidation induced by $\mathrm{Fe}^{3+}\left(\mathrm{Fe}^{3+}\right.$ catalyses $\mathrm{H}_{2} \mathrm{O}_{2}$ to 235 produce hydroxyl radicals).

236 For monitoring the subtle changes in physical and chemical states of proteins, surface 237 hydrophobicity is a suitable parameter (Sante-Lhoutellier et al., 2007). As shown in 238 Table 1, compared with the control, the hydrophobicity of $\mathrm{MP}\left(0 \mathrm{mM} \mathrm{H} \mathrm{H}_{2} \mathrm{O}_{2}\right)$ 239 significantly increased $(p<0.05)$, implying that the addition of ascorbic acid, $\mathrm{Fe}^{3+}$ and 240 oxidative terminators may markedly increase the protein surface hydrophobicity. In 241 addition, surface hydrophobicity of MP gradually increased with the increase of $\mathrm{H}_{2} \mathrm{O}_{2}$ 242 concentrations $(0.05-5.0 \mathrm{mM})$, and the results were similar to those of some previous 243 reports (Cao et al., 2018; Sun et al., 2013). Chelh et al. (2006) suggested that the 244 increase of surface hydrophobicity could be attributed to the unfolding of MP, thus 245 exposing previously buried nonpolar amino acids at their surface. Oxidative damage 246 could induce partial unfolding of MP, thereby exposing the hydrophobic amino acids 247 that were normally buried in protein molecules (Estévez, 2011; Sante-Lhoutellier et al., 248 2007). Moreover, the cleavage of certain peptides under oxidative stress may also result 249 in the enhancement of surface hydrophobicity (Pacifici, 1987).

250 Salt solubility can reflect the extent of proteins aggregation (Shen et al., 2019). As 251 shown in Table 1, compared with the control, salt solubility of MP revealed a slight 252 increase $(1.19-3.43 \% ; p<0.05)$ with low concentrations of oxidant $(0-0.2 \mathrm{mM})$, and 253 then exhibited a rapid decrease $(0.59-51.36 \% ; p<0.05)$ for the further oxidant 
treatments $(0.5-5.0 \mathrm{mM})$. A slight oxidation could cause a subtle unfolding of proteins

255 (Estévez, 2011), which may lead to better solubility in the salt solution. Nevertheless,

256 with further increase in oxidant, the solubility of MP drastically decreased due to the

257 stronger oxidative attack. This could be explained by the enhancement of surface

258 hydrophobicity and the excessive protein aggregates (Sun, Li, Zhou, Zhao, \& Zhao, 259 2014). The exposure of hydrophobic patches or individual groups, aggregation and 260 polymerisation through $\mathrm{S}-\mathrm{S}$ are all associated with the solubility decrease (Li, Xiong, 261 \& Chen, 2012).

262 Turbidity is attributed to the presence of protein aggregates. The turbidity of MP 263 suspensions (Table 1) increased $(p<0.05)$ with the increased addition of $\mathrm{H}_{2} \mathrm{O}_{2}(0-5.0$ $264 \mathrm{mM}$ ), which accorded with the loss of SH and the increase of surface hydrophobicity.

265 This indicated that the oxidised incubation could obviously enhance the aggregation 266 behaviour of proteins. Under further analysis, this phenomenon was noted to be caused 267 by the increased surface hydrophobicity due to the exposure of interior hydrophobic 268 amino acid residues and the formation of intra- and intermolecular cross-links under 269 oxidative attack ( $\mathrm{Li}$ et al., 2012), thus leading to the turbidity increase of MP 270 suspensions.

\section{3.2. Particle size distributions}

272 Particle size distributions can be used to monitor the aggregation behaviours of 273 proteins under oxidative attack. As shown in Fig. S1, compared with the control, the 274 particle size distribution of MP exhibited an obvious shift towards larger particles with 275 the increase of $\mathrm{H}_{2} \mathrm{O}_{2}$ concentrations. Protein oxidation could promote intermolecular 276 aggregation behaviours between protein molecules, thus increasing the particle size 277 values (Xiong et al., 2009). Specifically, the $\mathrm{D}_{3,2}$ value of MP after oxidation showed 278 no significant difference $(p>0.05)$, while the values for other particle sizes $\left(\mathrm{D}_{4,3}\right.$ and 
$279 \mathrm{D}_{\mathrm{v}, 0.5)}$ (Table 2) increased significantly $(p<0.05)$. The large droplets or droplet 280 aggregates have higher weight in the calculation of the $\mathrm{D}_{4,3}$ value than they do in the 281 calculation of the $\mathrm{D}_{3,2}$ value, and samples with similar $\mathrm{D}_{3,2}$, but different $\mathrm{D}_{4,3}$ would 282 result primarily from the amount of large droplets or droplet aggregates (Sun et al. 283 2014). This indicates that protein aggregation occurred after oxidation. Moreover, the 284 SH, surface hydrophobicity and turbidity analysis (Table 1) conformed to the 285 enhancement of association behaviours between protein molecules with the increase of $286 \mathrm{H}_{2} \mathrm{O}_{2}$ concentrations, thereby enlarging the diameter of particles.

\subsection{SDS-PAGE}

288 The aggregation behaviours of the control and oxidised MP were further studied 289 using SDS-PAGE analysis (Fig. S2). In the absence of dithiothreitol, a large polymer 290 appeared at the top of the stack gel (Fig. S2A), suggesting the aggregation of MP. In 291 addition, MP aggregates induced by oxidative attack could form much larger aggregates 292 that could not enter the gel. Moreover, the intensities of the aggregation bands and the 293 aggregates all decreased and were not recovered in the presence of dithiothreitol (Fig.

294 S2B). This phenomenon indicated that the cross-links of the MP induced by oxidation 295 were not only through S-S but also through other covalent bonds (Cao et al., 2016). As 296 shown in the comparison between Fig. S2A and Fig. S2B, myosin heavy chain (MHC), $297 \alpha$-actinin and actin participated in the formation of aggregates.

298 3.4. Gel properties

299 3.4.1. Hardness and WHC

300 As aforementioned, oxidation had a pronounced effect on the physicochemical states 301 of MP. The hardness (Fig. 1A) and WHC (Fig. 1B) of the control and oxidised MP gels 302 were further evaluated. The mean hardness of the control gel was $21.9 \pm 1.4 \mathrm{~g}$ and this 303 value was similar to that found by Xu, Han, Fei, and Zhou (2011). Compared with the 
control, the hardness of mildly oxidised MP gels $\left(0-0.2 \mathrm{mM} \mathrm{H}_{2} \mathrm{O}_{2}\right)$ increased significantly $(p<0.05)$. Due to the slightly unfolding of MP (salt solubility analysis), a

306 firmer matrix structure of MP gels may be formed during the heating process. Xiong et 307 al. (2010) also suggested that mild oxidation could promote protein network formation 308 and enhance the gelation of MP. Nevertheless, with more addition of $\mathrm{H}_{2} \mathrm{O}_{2}(0.5-5.0$ $309 \mathrm{mM})$, a significant decrease $(p<0.05)$ in gel hardness was observed, implying a weak 310 gel structure. In particular, heat-induced S-S bonds were regarded as an important 311 supporting force for the matrix structure of protein gels (Xiong et al., 2010). Hence, the 312 decrease of hardness may be attributed to the reduction of SH contents in MP (Table 313 1), thus leading to disordered aggregation replacing the ordered cross-links during 314 heating. Moreover, the decrease of salt solubility of MP could limit the ordered cross315 links within protein molecules during gelation.

316 Furthermore, WHC gave a quantitative indication of the amount of water maintained 317 within the protein gel structure, and this could reflect aspects of the spatial structure of 318 the gel (Zhou et al., 2014b). As shown in Fig. 1B, the control gel had the strongest 319 ability to retain water, and the WHC abilities of oxidised MP gels were gradually 320 weakened $(p<0.05)$ with an increase of $\mathrm{H}_{2} \mathrm{O}_{2}$ concentration $(0-5.0 \mathrm{mM})$. As reported,

321 the structural integrity of myosin is of paramount importance for gelation and water 322 holding in meat (Deng et al., 2010). Oxidative damage to myosin could result in an 323 inferior gel network formation, causing lower elasticity with poor WHC in the gel 324 matrix. This was in good agreement with the surface hydrophobicity of MP (Table 1), 325 which could also reflect the affinity of proteins with water.

\subsubsection{Microstructure}

327 The changes in MP gel properties induced by oxidation were further investigated by 328 the measurements of surface morphologies, and the results are presented in Fig. 2. The 
329 control gel appeared as a flat surface with several visible pores (Fig. 2A and 2B), which

330 indicated an ordered network structure due to protein stretching. At 2000 times 331 magnification, the protein (control gel) exhibits a good cross-linked structure. 332 Compared to the control, the mildly oxidised MP gels $\left(0-0.2 \mathrm{mM} \mathrm{H}_{2} \mathrm{O}_{2}\right)$ exhibited some 333 fragments on the gel surface and a lower number of visible pores (Fig. 2B). The pore 334 size of these gel was significantly reduced $(\times 500)$, and the original cross-linked 335 structure was transformed into an aggregated particle structure, and the roughness is 336 increased ( $\times$ 2000), thereby yielding a firm pattern (hardness analysis). This 337 phenomenon was attributed to the slight shrinkage of MP upon oxidation (Astruc, 338 Gatellier, Labas, Lhoutellier, \& Marinova, 2010). As a continuous increase of $\mathrm{H}_{2} \mathrm{O}_{2}$ $339(0.5-1.0 \mathrm{mM})$, aggregated particles and roughness further increased with the much 340 more smaller pore size. Under $5 \mathrm{mM} \mathrm{H}_{2} \mathrm{O}_{2}$, the pores disappeared, and the fragments 341 aggregated into clump structures. The surface morphologies of these gels revealed an 342 uneven dense structure with aggregates and increased the roughness of the overlapped 343 surface. This trend was in accordance with a previous observation (Zhou et al., 2014a).

344 Formation of the surface structures of oxidised MP gels described previously could be 345 attributed to the intra- and intermolecular cross-links and aggregates within proteins 346 induced by oxiditive modification (Sun et al., 2014), thus leading to a disordered gel 347 network structure during the heating process. In addition, the clump structures clearly 348 aggregated into larger globular clusters when subjected to higher oxidative attack (2.5$3495.0 \mathrm{mM} \mathrm{H}_{2} \mathrm{O}_{2}$ ), indicating an accelerated state of aggregation (Fig. 2B). These structural 350 features implied that proteins under higher oxidative stress could undergo more steric 351 modifications and contribute to the layered surface with bunched aggregation (Zhou et 352 al., 2014a). These micrographs demonstrated the significant influences of oxidative 353 treatments on protein gels. Moreover, these observations were in agreement with the 
results of SH contents, surface hydrophobicity, turbidity and particle size distributions

355 (Table 1 and Fig. S1).

\subsubsection{Relaxation time analysis}

A fitted $\mathrm{T}_{2}$ distribution was used to assess the relaxation time of hydrogen protons.

The $\mathrm{T}_{2}$ relaxation time distributions for the control and oxidised MP gels are shown in

359 Fig. 3. Three peaks were noted for the control and in the gels with lower $\mathrm{H}_{2} \mathrm{O}_{2}$ 360 concentrations $(0-1.0 \mathrm{mM})$, while four peaks were noted for the gels with $2.5-5.0 \mathrm{mM}$

$361 \mathrm{H}_{2} \mathrm{O}_{2}$. This meant that the protein gels under different oxidation levels could restrict 362 water mobility at different magnitudes (Wang, Zhang, Bhandari, \& Gao, 2016). The 363 components with shorter relaxation time, $\mathrm{T}_{2 \mathrm{~b}}$ and $\mathrm{T}_{21}(0-10 \mathrm{~ms})$, represented the protons 364 in macromolecular structures and those combined closely with the macromolecular 365 structures, respectively. The component $\mathrm{T}_{22}(10-100 \mathrm{~ms})$ was assigned to myofibrillar 366 water and water within the protein structure. The last peak represented the extra367 myofibrillar water $\left(\mathrm{T}_{23}\right)$ population, and this peak appeared between 300 and $2000 \mathrm{~ms}$.

368 Generally, the existence of four groups of water in MP gels was in agreement with some 369 previous reports (Wang et al., 2016; Zheng et al., 2015).

370 With oxidation treatments, the relaxation time of $\mathrm{T}_{22}$ increased from $14.17 \mathrm{~ms}$ 371 (control gel) to $16.30-28.48 \mathrm{~ms}$ (oxidised gels) with increasing $\mathrm{H}_{2} \mathrm{O}_{2}$ concentrations, 372 and $\mathrm{T}_{23}$ increased from $613.59 \mathrm{~ms}$ (control and oxidised gels with 0-1.0 $\mathrm{mM} \mathrm{H}_{2} \mathrm{O}_{2}$ ) to $373705.48 \mathrm{~ms}$ (oxidised gels with 2.5-5.0 $\mathrm{mM} \mathrm{H}_{2} \mathrm{O}_{2}$ ) (Table 1S). If the relaxation time is 374 shorter, a smaller amount of mobile water is available, whereas the longer relaxation 375 time implies a more mobile water fraction (Shao et al., 2016). Hence, the increased $\mathrm{T}_{2}$ 376 relaxation times suggested that oxiditive modifications could lead to a certain level of 377 the immobilised water shifting to free water. This may be associated with the 378 enhancement in hydrophobic trend arising from the increased surface hydrophobicity 
of MP (Table 1). Also, the increased aggregation behaviours (Fig. S1 and Table 2) within MP molecules could decrease the surface areas in gels, thus resulting in a decrease of macromolecule sites for WHC (Wang et al., 2016). Moreover, the relaxation component $\mathrm{T}_{2 \mathrm{~b}}$ had divided into another part $\left(\mathrm{T}_{21}\right)$ at higher $\mathrm{H}_{2} \mathrm{O}_{2}$ concentrations (2.5$5.0 \mathrm{mM}$ ). This may be due to the degradation of MP upon higher oxidative stress, thus contributing to greater mobility of the water in macromolecular structures. In addition, McDonnell et al. (2013) suggested that certain side-chains, such as carboxyl-, amino-, hydroxyl-, sulfhydryl-groups, and even carbonyl- and imido-groups, in proteins were responsible for water binding. Therefore, the changes in $\mathrm{T}_{2 \mathrm{~b}}$ relaxation time 388 corresponded to the availability of protein side-chains, as related to the oxidative modifications. These phenomena accorded with the WHC results (Fig. 1B).

\subsection{Binding of MP gels to flavours}

391 A homologous series of aldehydes and ketones that varied in chain length was 392 selected to investigate the binding performances of MP gels under different oxidation 393 levels. In protein solution systems, the longer the carbon chain, the stronger the ability 394 of the flavour compound to bind to the protein. (Lou, Yang, Sun, Pan, \& Cao, 2017; 395 Zhou et al., 2014a). By contrast, in this study, the free percentages of aldehydes and 396 ketones in each vial increased with the increase in carbon chain length (Fig. 4), 397 suggesting it was more difficult for the flavour compounds with longer chain length to 398 bind with MP gels, which can be related to the steric effect of the gel network structure. 399 In addition, consistent with the finding reported by Wang and Arntfield (2015), the free 400 percentage of all aldehydes was lower than that of the ketones with the same carbon 401 numbers in all vials (Fig. 4), suggesting that the binding abilities of oxidised MP gels 402 to aldehydes were stronger than to ketones. This was because of the higher molecular 
403 activities and lower steric hindrance effects of carbonyl groups in aldehydes (Kühn et 404 al., 2008).

405 As shown in Fig. 4A, the free percentages of hexanal and heptanal first decreased 406 and then increased significantly $(\mathrm{p}<0.05)$ with increased oxidation levels $(0-5.0 \mathrm{mM})$. 407 Although the free percentages of pentanal and octanal showed no significant changes $408(\mathrm{p}>0.05)$ at different oxidation levels, their trends were similar to those of hexanal and 409 heptanal. The free percentages of ketones (Fig. 4B) (except for 2-octanone) showed no 410 significant changes at different oxidation levels $(0-5.0 \mathrm{mM})$. Volatile release from food 411 is primarily controlled by the following two factors: the nature of aroma compounds 412 (such as volatility and polarity) and the resistance to mass transfer from a food matrix 413 to the air phase (Mao, Roots, \& Miao, 2015). Protein oxidation increased the surface 414 hydrophobicity and interaction of proteins (Table 1); the oxidised MP gels could 415 exhibit higher binding phenomena through stronger interaction force (such as 416 hydrophobic interaction) to flavours, thus reducing their free percentages in the 417 headspace. However, the binding of a certain protein gel to flavours may also be 418 influenced by the steric hindrance effect or mass transfer from MP gel. Therefore, 419 flavours with a longer carbon chain could produce a stronger steric hindrance effect due 420 to the gel network, thus preventing their access to the interior hydrophobic binding sites 421 and thus increasing their presence in the headspace (Wang \& Arntfield, 2015). As 422 shown in Fig. 2, as the degree of oxidation increased, the homogeneous cross-linked 423 MP gel network gradually changes to a granular shape, and gradually loses the gel 424 network structure (the pore size of the gel network also gradually decreases), which 425 increases the steric resistance of the MP gel, increasing the content of aroma 426 components in the headspace vial. Therefore, the release of flavour compounds 
depended on the balance between protein-flavour compound interactions and gel network-flavour compound limitations (Mao et al., 2014).

429

430

\section{Conclusions}

The influence of oxidative modifications induced by $\mathrm{H}_{2} \mathrm{O}_{2}(0-5.0 \mathrm{mM})$ on the properties of MP and MP gels was investigated. With an increase in $\mathrm{H}_{2} \mathrm{O}_{2}$ concentrations, MP tended to expose their interior hydrophobic amino acids and to lose SH content, thus leading to enhanced aggregation behaviours, an increase in surface hydrophobicity and turbidity and a larger particle size distribution. The covalent bonds in the MP aggregates included $\mathrm{S}-\mathrm{S}$, among others. Under oxidative attack, MP gels demonstrated decreased WHC and more mobility of water. Mild oxidation $(0-0.5 \mathrm{mM}$ $\mathrm{H}_{2} \mathrm{O}_{2}$ ) slightly increased the salt solubility of MP and the hardness of MP gels. The abilities of MP gels to bind to aldehydes and ketones decreased with the growth of the carbon chain. The release of flavours in a gel was different from that in a protein solution due to mass transfer from a gel matrix to the air phase and heat treatment. Under the balance between protein-flavour compound interaction and gel networkflavour compound steric hindrance, MP oxidation only significantly affected $(p<0.05)$ the binding between MP gels and hexanal, heptanal, and 2-octanone, while other flavour compounds were not affected significantly $(p>0.05)$.

\section{Acknowledgement}

This work was supported by the National Natural Science Foundation of China (31671870); the National Key R\&D Program of China (2016YFD0401504); the China Scholarship Council (201906155018); the Science and Technology Program of Guangzhou (201807010102); the Science and Technology Program of Guangdong (2016B020203001) and the 111 Project (B17018). 


\section{References}

454 Astruc, T., Gatellier, P., Labas, R., Lhoutellier, V. S., \& Marinova, P. (2010). 455 Microstructural changes in $m$. rectus abdominis bovine muscle after heating. Meat $456 \quad$ Science, 85(4), 743-751.

457 Boland, A. B., Delahunty, C. M., \& van Ruth, S. M. (2006). Influence of the texture of 458 gelatin gels and pectin gels on strawberry flavour release and perception. Food 459 Chemistry, 96(3), 452-460.

460 Cao, Y., True, A. D., Chen, J., \& Xiong, Y. L. (2016). Dual Role (Anti- and Pro-oxidant) 461 of Gallic Acid in Mediating Myofibrillar Protein Gelation and Gel in Vitro 462 Digestion. Journal of Agricultural and Food Chemistry, 64(15), 3054-3061.

463 Chelh, I., Gatellier, P., \& Santé-Lhoutellier, V. (2006). Technical note: A simplified procedure for myofibril hydrophobicity determination. Meat Science, 74(4), 681683.

Deng, Y., Rosenvold, K., Karlsson, A. H., Horn, P., Hedegaard, J., Steffensen, C. L., \& Andersen, H. J. (2010). Relationship Between Thermal Denaturation of Porcine Muscle Proteins and Water-holding Capacity. Journal of Food Science, 67(5), $1642-1647$.

Estévez, M. (2011). Protein carbonyls in meat systems: A review. Meat Science, 89(3), 259-279.

472 Gierczynski, I., Guichard, E., \& Laboure, H. (2011). Aroma perception in dairy products: the roles of texture, aroma release and consumer physiology. A review. Flavour and Fragrance Journal, 26(3), 141-152.

475 Guichard, E. (2002). Interactions between flavor compounds and food ingredients and their influence on flavor perception. Food Reviews International, 18(1), 49-70. 
Guinard, J. X., \& Marty, C. (1995). Time-intensity measurement of flavor release from a model gel system: effect of gelling agent type and concentration. Journal of Food Science, 60(4), 727-730.

Hansson, A., Giannouli, P., \& van Ruth, S. (2003). The influence of gel strength on aroma release from pectin gels in a model mouth and in vivo, monitored with proton-transfer-reaction mass spectrometry. Journal of Agricultural and Food Chemistry, 51(16), 4732-4740.

Juteau-Vigier, A., Atlan, S., Deleris, I., Guichard, E., Souchon, I., \& Trelea, I. C. (2007). Ethyl hexanoate transfer modeling in carrageenan matrices for determination of diffusion and partition properties. Journal of Agricultural and Food Chemistry, 55(9), 3577-3584.

Kühn, J., Considine, T., \& Singh, H. (2008). Binding of flavor compounds and whey protein isolate as affected by heat and high pressure treatments. Journal of Agricultural and Food Chemistry, 56(21), 10218-10224.

Lee, H. A., Choi, S. J., \& Moon, T. W. (2006). Characteristics of sodium caseinate- and soy protein isolate-stabilized emulsion-gels formed by microbial transglutaminase. Journal of Food Science, 71(6), C352-C357.

Li, C., Xiong, Y. L., \& Chen, J. (2012). Oxidation-induced unfolding facilitates Myosin cross-linking in myofibrillar protein by microbial transglutaminase. Journal of Agricultural \& Food Chemistry, 60(32), 8020-8027.

Lou, X., Yang, Q., Sun, Y., Pan, D., \& Cao, J. (2017). The effect of microwave on the interaction of flavour compounds with G-actin from grass carp (Catenopharyngodon idella). Journal of the Science of Food and Agriculture, 97(12), 3917-3922. 
501 Mao, L., Roos, Y. H., \& Miao, S. (2014). Study on the rheological properties and volatile release of cold-set emulsion-filled protein gels. Journal of Agricultural and Food Chemistry, 62(47), 11420-11428.

Mao, L., Roos, Y. H., \& Miao, S. (2015). Effect of maltodextrins on the stability and release of volatile compounds of oil-in-water emulsions subjected to freeze-thaw treatment. Food Hydrocolloids, 50, 219-227.

McDonnell, C. K., Allen, P., Duggan, E., Arimi, J. M., Casey, E., Duane, G., \& Lyng, J. G. (2013). The effect of salt and fibre direction on water dynamics, distribution and mobility in pork muscle: a low field NMR study. Meat Science, 95(1), 51-58.

O'Neill, T. E., \& Kinsella, J. E. (1987). Binding of alkanone flavors to $\beta$-lactoglobulin: effects of conformational and chemical modification. Journal of Agricultural and Food Chemistry, 35(5), 770-774.

Pacifici, R. E. (1987). Protein damage and degradation by oxygen radicals. Journal of Biological Chemistry, 262(20), 9902-9907.

Sante-Lhoutellier, V., Aubry, L., \& Gatellier, P. (2007). Effect of oxidation on in vitro digestibility of skeletal muscle myofibrillar proteins. Journal of Agricultural \& Food Chemistry, 55(13), 5343-5348.

Shao, J. H., Deng, Y. M., Song, L., Batur, A., Jia, N., \& Liu, D. Y. (2016). Investigation the effects of protein hydration states on the mobility water and fat in meat batters by LF-NMR technique. LWT - Food Science and Technology, 66, 1-6.

Shen, H., Zhao, M., \& Sun, W. (2019). Effect of pH on the interaction of porcine myofibrillar proteins with pyrazine compounds. Food Chemistry, 287, 93-99.

Sun, W., Li, Q., Zhou, F., Zhao, H., \& Zhao, M. (2014). Surface characterization of oxidized myofibrils using X-ray photoelectron spectroscopy and scanning electron microscopy. Journal of Agricultural \& Food Chemistry, 62(30), 7507-7514. 
526 Sun, W., Zhou, F., Sun, D.-W., \& Zhao, M. (2013). Effect of Oxidation on the Emulsifying Properties of Myofibrillar Proteins. Food and Bioprocess Technology, 6(7), 1703-1712.

Wang, K., \& Arntfield, S. D. (2015). Binding of selected volatile flavour mixture to salt-extracted canola and pea proteins and effect of heat treatment on flavour binding. Food Hydrocolloids, 43, 410-417.

532 Wang, K., \& Arntfield, S. D. (2016). Modification of interactions between selected volatile flavour compounds and salt-extracted pea protein isolates using chemical and enzymatic approaches. Food Hydrocolloids, 61, 567-577.

Wang, L., Zhang, M., Bhandari, B., \& Gao, Z. (2016). Effects of malondialdehydeinduced protein modification on water functionality and physicochemical state of fish myofibrillar protein gel. Food Research International, 86, 131-139.

Xia, X., Kong, B., Xiong, Y., \& Ren, Y. (2010). Decreased gelling and emulsifying properties of myofibrillar protein from repeatedly frozen-thawed porcine longissimus muscle are due to protein denaturation and susceptibility to aggregation. Meat Science, 85(3), 481-486.

Xiong, Y., Blanchard, S. P., Ooizumi, T., \& Ma, Y. (2010). Hydroxyl radical and ferrylgenerating systems promote gel network formation of myofibrillar protein. Journal of Food Science, 75(2), C215-C221.

Xiong, Y. L., Park, D. K., \& Ooizumi, T. (2009). Variation in the cross-linking pattern of porcine myofibrillar protein exposed to three oxidative environments. Journal of Agricultural \& Food Chemistry, 57(1), 153-159. heat-induced gelation of pork myofibrillar proteins and its relationship with textural characteristic. Meat Science, 87(3), 159-164. 
551 Zhang, Z., Yang, Y., Tang, X., Chen, Y., \& You, Y. (2015). Chemical forces and water 552 holding capacity study of heat-induced myofibrillar protein gel as affected by high 553 pressure. Food Chemistry, 188, 111-118.

554 Zheng, H., Xiong, G., Han, M., Deng, S., Xu, X., \& Zhou, G. (2015). High 555 pressure/thermal combinations on texture and water holding capacity of chicken 556 batters. Innovative Food Science \& Emerging Technologies, 30, 8-14.

557 Zhou, F., Zhao, M., Su, G., \& Sun, W. (2014b). Binding of aroma compounds with 558 myofibrillar proteins modified by a hydroxyl-radical-induced oxidative system. $559 \quad$ Journal of Agricultural \& Food Chemistry, 62(39), 9544-9552.

560 Zhou, F., Zhao, M., Zhao, H., Sun, W., \& Cui, C. (2014a). Effects of oxidative 561 modification on gel properties of isolated porcine myofibrillar protein by peroxyl $562 \quad$ radicals. Meat Science, 96(4), 1432-1439. 
Table 1 Total and reactive sulfhydryl groups, surface hydrophobicity, salt solubility and turbidity of the control and oxidised MP

\begin{tabular}{cccccc}
\hline $\mathrm{H}_{2} \mathrm{O}_{2}(\mathrm{mM})$ & $\begin{array}{c}\text { Total sulfhydryl } \\
(\mathrm{nmol} / \mathrm{mg} \text { protein })\end{array}$ & $\begin{array}{c}\text { Reactive sulfhydryl } \\
(\mathrm{nmol} / \mathrm{mg} \text { protein })\end{array}$ & $\begin{array}{c}\text { Surface hydrophobicity } \\
(\mu \mathrm{g} \mathrm{BPB})\end{array}$ & $\begin{array}{c}\text { Salt solubility } \\
(\%)\end{array}$ & $\begin{array}{c}\text { Turbidity } \\
(\mathrm{FTU})\end{array}$ \\
\hline $\mathrm{Control}$ & $9.02 \pm 0.12 \mathrm{~g}$ & $8.45 \pm 0.09 \mathrm{~h}$ & $22.75 \pm 1.22 \mathrm{a}$ & $83.57 \pm 1.39 \mathrm{~d}$ & $83.11 \pm 0.82 \mathrm{a}$ \\
0.0 & $8.30 \pm 0.04 \mathrm{f}$ & $6.35 \pm 0.05 \mathrm{~g}$ & $38.02 \pm 0.86 \mathrm{bc}$ & $84.57 \pm 0.46 \mathrm{de}$ & $84.27 \pm 0.58 \mathrm{a}$ \\
0.05 & $8.19 \pm 0.02 \mathrm{f}$ & $5.99 \pm 0.07 \mathrm{f}$ & $36.57 \pm 2.15 \mathrm{~b}$ & $86.43 \pm 1.09 \mathrm{e}$ & $87.13 \pm 0.56 \mathrm{~b}$ \\
0.2 & $7.99 \pm 0.05 \mathrm{e}$ & $5.56 \pm 0.11 \mathrm{e}$ & $38.59 \pm 0.85 \mathrm{c}$ & $86.39 \pm 0.66 \mathrm{e}$ & $90.44 \pm 2.37 \mathrm{c}$ \\
0.5 & $6.95 \pm 0.03 \mathrm{~d}$ & $3.24 \pm 0.11 \mathrm{~d}$ & $41.26 \pm 0.72 \mathrm{~d}$ & $83.08 \pm 0.94 \mathrm{~d}$ & $91.71 \pm 1.99 \mathrm{c}$ \\
1.0 & $5.87 \pm 0.03 \mathrm{c}$ & $2.84 \pm 0.07 \mathrm{c}$ & $42.47 \pm 0.34 \mathrm{~d}$ & $79.28 \pm 2.73 \mathrm{c}$ & $92.74 \pm 0.91 \mathrm{c}$ \\
2.5 & $3.52 \pm 0.11 \mathrm{~b}$ & $1.82 \pm 0.05 \mathrm{~b}$ & $46.23 \pm 0.71 \mathrm{e}$ & $52.23 \pm 0.96 \mathrm{~b}$ & $97.05 \pm 1.47 \mathrm{~d}$ \\
5.0 & $1.01 \pm 0.05 \mathrm{a}$ & $0.37 \pm 0.03 \mathrm{a}$ & $49.88 \pm 1.08 \mathrm{f}$ & $40.65 \pm 1.02 \mathrm{a}$ & $96.70 \pm 0.90 \mathrm{~d}$
\end{tabular}

564 Values in the same column with different letters were significantly different $(p<0.05)$. 
565 Table 2 Average particle size $\left(\mathrm{D}_{3,2}\right.$ and $\left.\mathrm{D}_{4,3}\right)$ and span of the control and oxidised MP

\begin{tabular}{|c|c|c|c|c|}
\hline $\mathrm{H}_{2} \mathrm{O}_{2}(\mathrm{mM})$ & $\mathrm{D}_{3,2}(\mu \mathrm{m})$ & $\mathrm{D}_{4,3}(\mu \mathrm{m})$ & $\mathrm{D}_{\mathrm{v}, 0.5}(\mu \mathrm{m})$ & Span \\
\hline Control & $41.55 \pm 1.51 \mathrm{a}$ & $99.58 \pm 2.76 a$ & $69.57 \pm 1.63 \mathrm{a}$ & $2.89 \pm 0.05 \mathrm{ab}$ \\
\hline 0.0 & $50.93 \pm 0.84 b$ & $119.53 \pm 1.09 b$ & $86.79 \pm 1.30 b$ & $2.80 \pm 0.09 a$ \\
\hline 0.05 & $51.47 \pm 1.80 b$ & $120.12 \pm 3.39 b c$ & $86.18 \pm 3.36 b$ & $2.84 \pm 0.06 \mathrm{a}$ \\
\hline 0.2 & $51.06 \pm 1.58 b$ & $121.22 \pm 3.70 b c$ & $87.00 \pm 3.40 b$ & $2.86 \pm 0.03 a$ \\
\hline 0.5 & $51.53 \pm 1.19 b$ & $125.19 \pm 2.46 b c$ & $87.57 \pm 2.03 b$ & $3.01 \pm 0.03 b c$ \\
\hline 1.0 & $48.80 \pm 1.90 b$ & $126.49 \pm 4.66 c$ & $87.62 \pm 3.70 b$ & $3.11 \pm 0.03 \mathrm{~cd}$ \\
\hline 2.5 & $50.72 \pm 2.12 b$ & $138.31 \pm 4.05 \mathrm{~d}$ & $96.93 \pm 3.48 c$ & $3.12 \pm 0.06 \mathrm{~cd}$ \\
\hline 5.0 & $51.77 \pm 2.21 b$ & $146.12 \pm 5.07 \mathrm{e}$ & $101.82 \pm 4.95 c$ & $3.18 \pm 0.17 \mathrm{~d}$ \\
\hline
\end{tabular}


Figure Captions:

568 Fig. 1. Hardness (A) and WHC (B) of the control and oxidised MP gels. Different letters

569 denote a significant difference between means $(p<0.05)$.

570 Fig. 2. Scanning electron microscope micrographs at $\times 500$ (A) and $\times 2000$ (B)

571 magnification of the control and oxidised MP gels. Scale bars indicate $100 \mu \mathrm{m}(\mathrm{A})$ and

$57220 \mu \mathrm{m}(\mathrm{B})$.

573 Fig. 3. Distributions of $\mathrm{T}_{2}$ relaxation times of the control and oxidised MP gels.

574 Fig. 4. Binding phenomena of the control and oxidised MP gels to selected aldehydes

575 (A) and ketones (B). Results were expressed as percentage of free flavours found in the 576 headspace of the control gel. Capital letters denote significant differences $(p<0.05)$ in 577 flavour compound release for a same oxidant concentration, while lowercase letters 578 denote significant differences $(p<0.05)$ in compound release between oxidant 579 concentrations. 

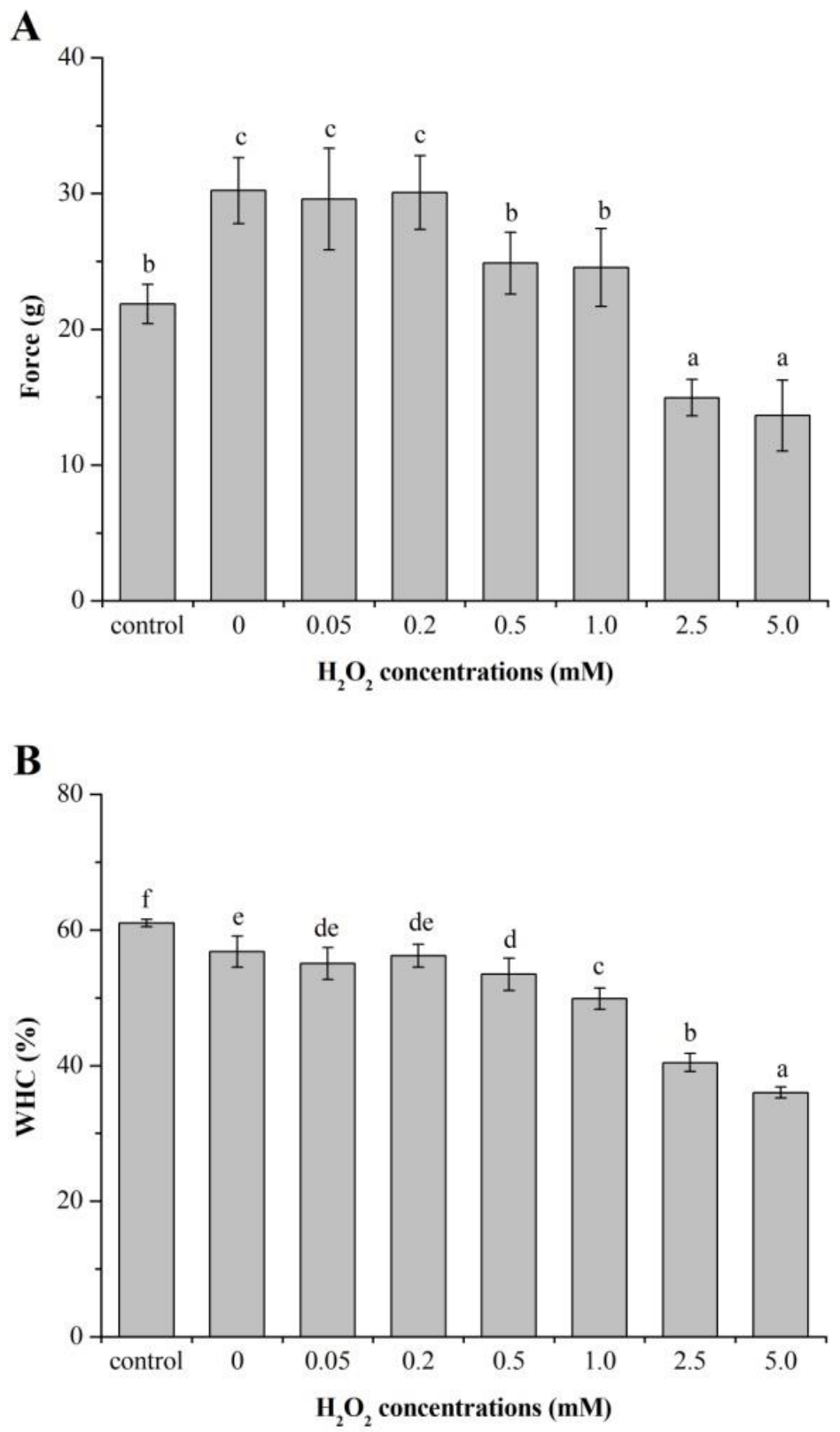

$582 \quad$ Fig. 1 

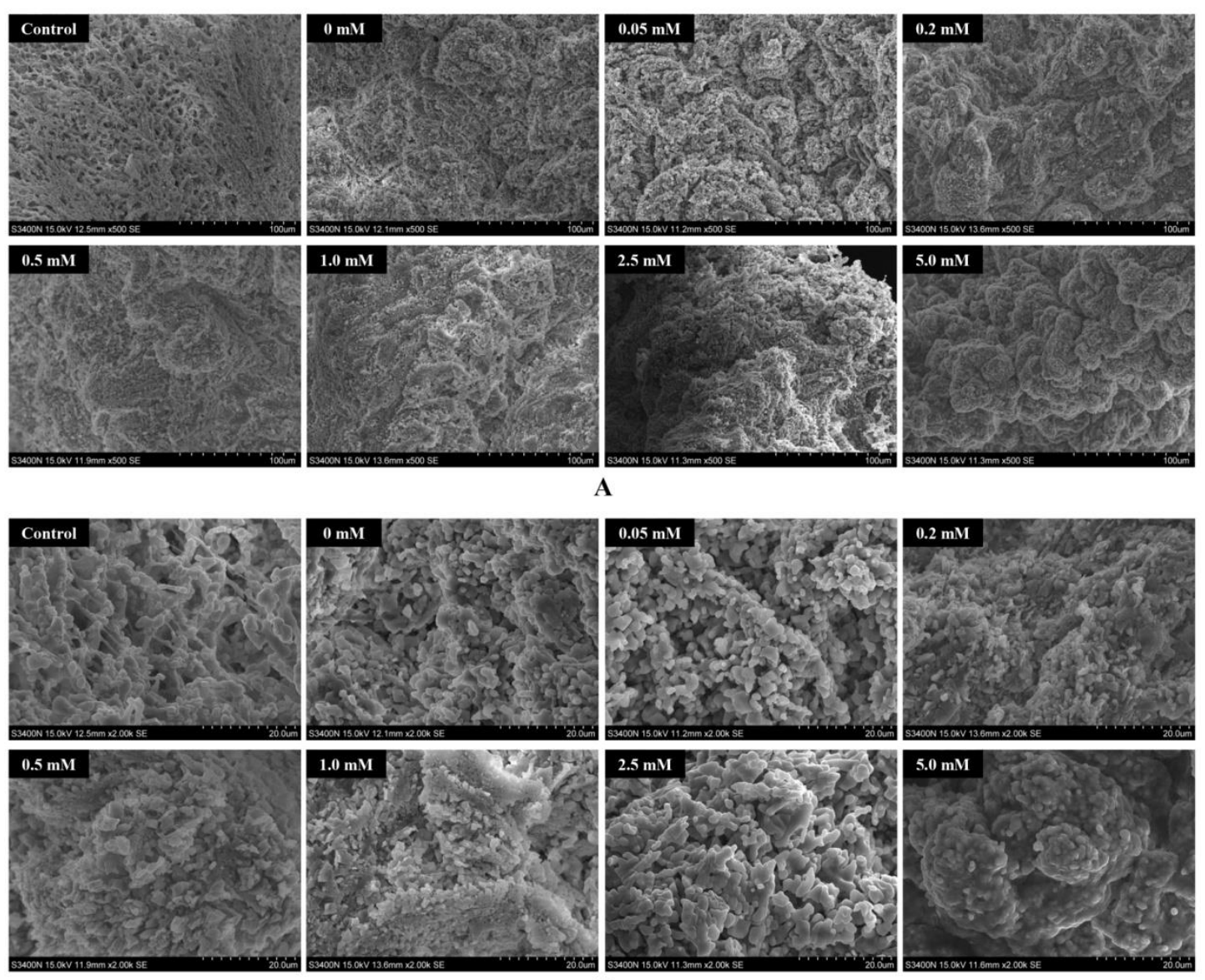

583
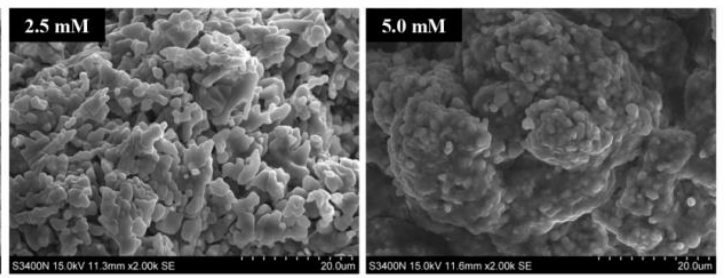

$584 \quad$ Fig. 2 


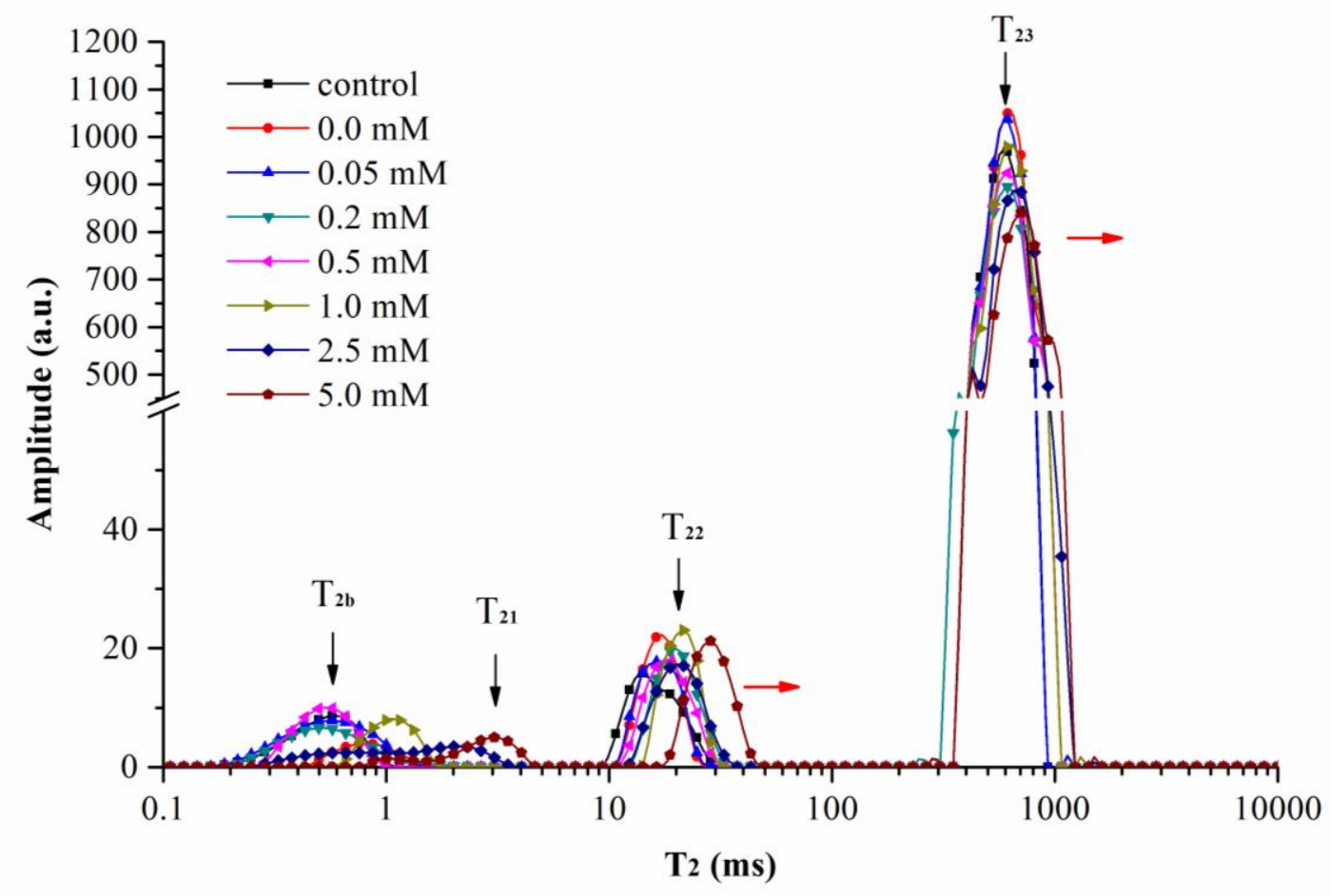

585

586 Fig. 3 


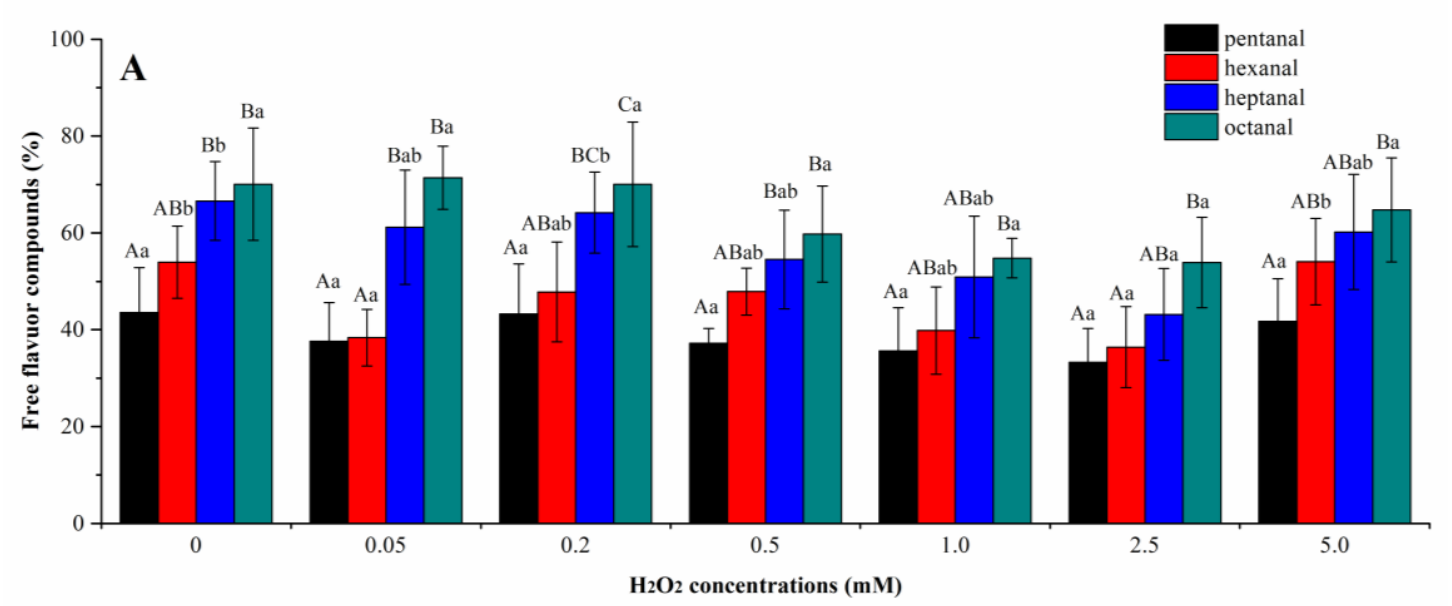

587

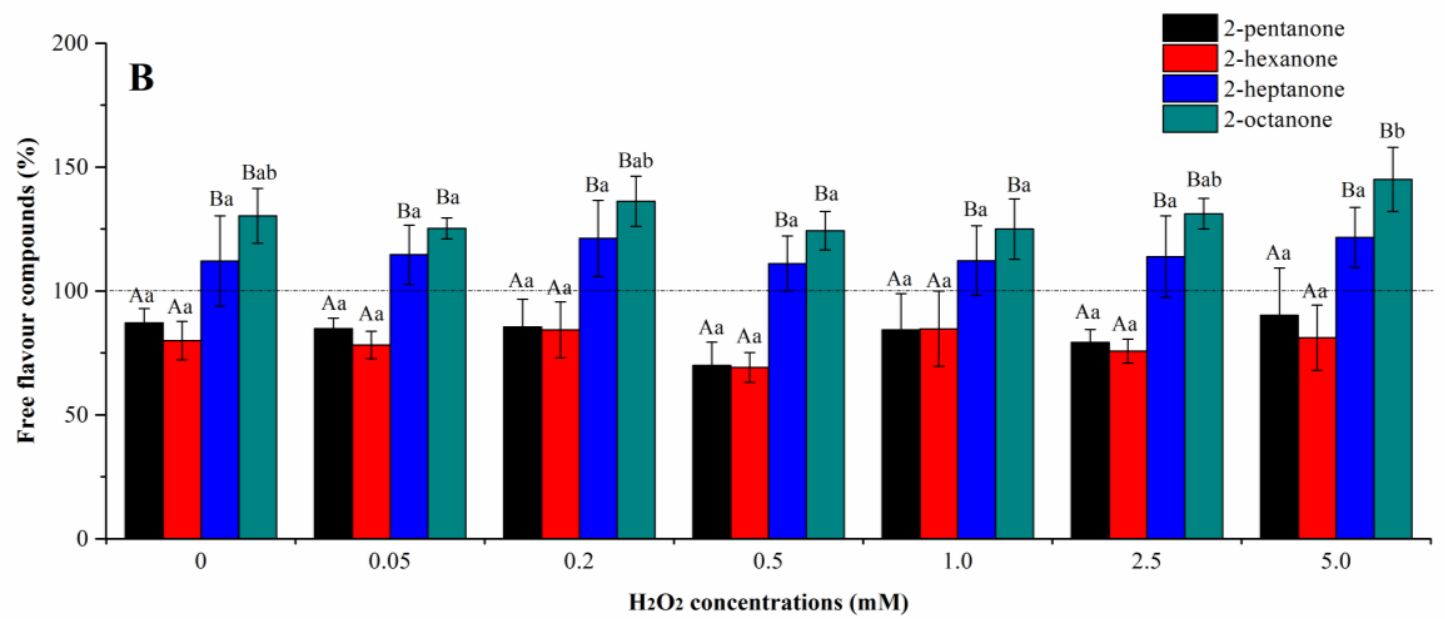

588

$589 \quad$ Fig. 4 